\title{
The pycnometer challenge
}

\author{
Olaf Rienitz • Axel Pramann • Carola Pape
}

(C) Springer-Verlag Berlin Heidelberg 2013

We would like to invite you to participate in the Analytical Challenge, a series of puzzles to entertain and challenge our readers. This special feature of "Analytical and Bioanalytical Chemistry" (ABC) has established itself as a truly unique quiz series, with a new scientific puzzle published every other month. Readers can access the complete collection of published problems with their solutions on the $A B C$ homepage at $\mathrm{http}: / / \mathrm{www}$. springer.com/abc. Test your knowledge and tease your wits in diverse areas of analytical and bioanalytical chemistry by viewing this collection.

In the present challenge, determination of density is the topic. And please note that there is a prize to be won (a Springer book of your choice up to a value of €100). Please read on...

\section{Meet the pycnometer challenge}

When we place an object on a balance, for example, a plastic bottle containing a standard solution, the resulting mass we read (the so-called apparent mass, $m^{\prime}$ ) is usually smaller than the actual mass of the object by an amount equal to the mass of the air displaced by the object. This effect can be corrected for by applying an air buoyancy correction factor $K$ to the apparent mass $m^{\prime}$ in order to yield the actual mass $m$ :

$$
m_{i}=K_{i} m_{i}^{\prime}, \quad \text { with } \quad K_{i}=\frac{1-\rho_{\text {air }} / \rho_{\text {cal }}}{1-\rho_{\text {air }} / \rho_{i}} .
$$

O. Rienitz $(\bowtie) \cdot$ A. Pramann $\cdot$ C. Pape

Physikalisch-Technische Bundesanstalt (PTB), Bundesallee 100, 38116 Braunschweig, Germany

e-mail: olaf.rienitz@ptb.de
This correction factor depends on the density of the surrounding air, $\rho_{\text {air }}$, on the density of the weight that has been used to calibrate the balance (usually stainless steel, $\rho_{\text {cal }}=8000 \mathrm{~kg} / \mathrm{m}^{3}$ ), and on the density of the object itself, $\rho_{i}$. Figure 1 shows the difference between apparent and actual mass as a function of the density $\rho_{i}$. In the case of aqueous solutions, the balance will indicate an apparent mass that is biased by more than $0.1 \%$.

When the highest accuracy is demanded, the air buoyancy correction can no longer be disregarded [1]. Although most of the densities required in a chemist's life, such as those of metals, salts, or various plastics, are compiled in textbooks, one has to determine the density of solutions in-house. The question therefore arises of how to determine those densities. A traditional method, dating back to the work of Guy-Lussac

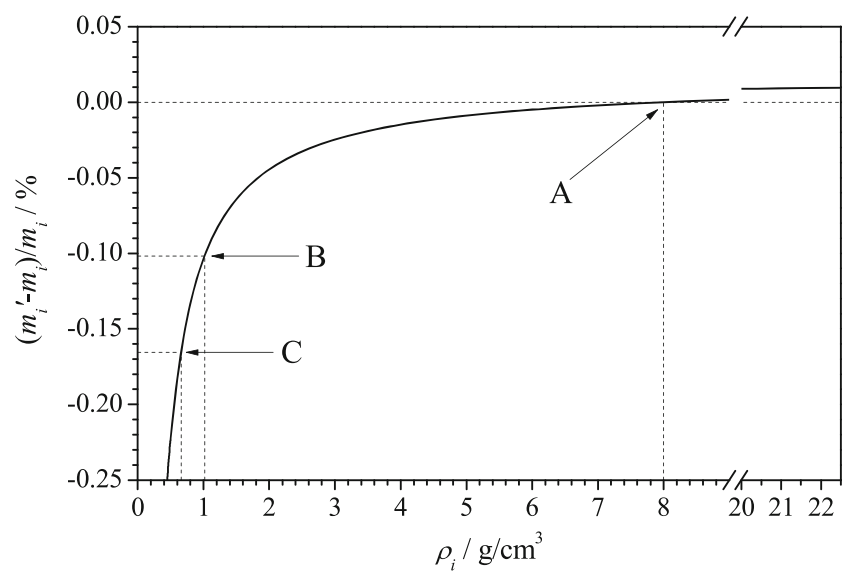

Fig. 1 The difference between apparent and actual mass as a function of the sample density, $\rho_{i}$. When the object on the balance has a density of $8 \mathrm{~g} / \mathrm{cm}^{3}$ (the same as the stainless-steel weight used to calibrate the balance), this difference disappears (A). $\mathbf{B}$ and $\mathbf{C}$ depict the situations for an aqueous tetramethylammonium hydroxide $(T M A H)$ solution $[w($ TMAH $)=0.25 \mathrm{~g} / \mathrm{g}]$ and $n$-hexane, respectively. The ambient conditions were as follows: air pressure $1013 \mathrm{hPa}$, relative humidity $0.50 \mathrm{~g} / \mathrm{g}$ (equivalent to $50 \%$ ), and room temperature $23.0{ }^{\circ} \mathrm{C}$ 
Table 1 Measured (apparent) masses needed to calculate the density of the tetramethylammonium hydroxide (TMAH) solution and relevant ambient conditions

\begin{tabular}{|c|c|c|c|c|c|c|c|}
\hline Time & Object & $i$ & $m^{\prime} / \mathrm{g}$ & $p / \mathrm{hPa}$ & $h /(\mathrm{g} / \mathrm{g})$ & $\vartheta /{ }^{\circ} \mathrm{C}$ & $\rho_{\text {air }} /\left(\mathrm{kg} / \mathrm{m}^{3}\right)$ \\
\hline$t_{1}$ & $\begin{array}{l}\text { Empty pycnometer } \\
\text { Pycnometer with pure water }\end{array}$ & $\begin{array}{l}\mathrm{p} 1 \\
\mathrm{p}+\mathrm{w}\end{array}$ & $\begin{array}{l}10.0348 \\
15.0216\end{array}$ & 1005 & 0.680 & 21.5 & 1.18073 \\
\hline$t_{2}$ & $\begin{array}{l}\text { Empty pycnometer } \\
\text { Pycnometer with TMAH solution }\end{array}$ & $\begin{array}{l}\mathrm{p} 2 \\
\mathrm{p}+\mathrm{s}\end{array}$ & $\begin{array}{l}10.0348 \\
15.1242\end{array}$ & 1005 & 0.753 & 21.5 & 1.17990 \\
\hline
\end{tabular}

The densities of quartz and air-free water $\left(\right.$ at $21.5^{\circ} \mathrm{C}$ ) are $2230 \mathrm{~kg} / \mathrm{m}^{3}$ and $997.880 \mathrm{~kg} / \mathrm{m}^{3}$, respectively [2]

in the early nineteenth century, is the use of a pycnometer. A pycnometer allows one to reproduce a particular volume very accurately. In turn, this volume can be established using a liquid with a known density, usually pure water. In practice, the dry pycnometer is weighed first $\left(m_{0}\right)$, then it is filled with water and weighed $\left(m_{1}\right)$, then it is emptied and filled with the sample liquid and weighed $\left(m_{2}\right)$. The density of the sample liquid can be obtained if one knows the density of water:

$\rho($ sample $)=\rho($ water $) \frac{m_{2}-m_{0}}{m_{1}-m_{0}}$.

To obtain the mass differences between the filled and empty pycnometer, however, one has to apply buoyancy corrections (because $K_{0} \neq K_{1} \neq K_{2}$ ). But to do that, one has to know the density of the material we are about to determine and which we therefore do not know yet. Sounds like a catch-22? Welcome to the challenge.

\section{The challenge}

We need to weigh accurately an aqueous solution of tetramethylammonium hydroxide $(\mathrm{TMAH}), w(\mathrm{TMAH})=$ $0.25 \mathrm{~g} / \mathrm{g}$, and therefore we have to determine the density of this solution using a pycnometer. To establish (calibrate) the volume of the pycnometer, the thoroughly cleaned and dried quartz pycnometer was weighed empty $\left(m_{\mathrm{p} 1}^{\prime}\right)$. After it had been filled with pure water, it was weighed again $\left(m_{\mathrm{p}+\mathrm{w}}^{\prime}\right)$. Then the pycnometer was dried and weighed before $\left(m_{\mathrm{p} 2}^{\prime}\right)$ and after $\left(m_{\mathrm{p}+\mathrm{s}}^{\prime}\right)$ it had been filled with the sample. Each time, the pycnometer, water, and TMAH solution were allowed to equilibrate to room temperature. Between the calibration of the pycnometer (time $t_{1}$ ) and the measurement of the TMAH solution (time $t_{2}$ ), the ambient conditions had changed. Therefore, in addition to the apparent masses (empty pycnometer $m_{\mathrm{p} 1}^{\prime}$ at $t_{1}$, pycnometer with pure water $m_{\mathrm{p}+\mathrm{w}}^{\prime}$, empty pycnometer $m_{\mathrm{p} 2}^{\prime}$ at $t_{2}$, and pycnometer with TMAH $m_{\mathrm{p}+\mathrm{s}}^{\prime}$ ), the ambient conditions - air pressure $p$, relative humidity $h$, and room temperature $\vartheta$-were also measured.

Despite the apparent catch-22 arising from Eqs. 1 and 2, calculate the density of the TMAH solution using the data compiled in Table 1.
There are two pathways to calculate the density of the TMAH solution: (1) an iterative solution using Eqs. 1 and 2, which requires a first guess for the density calculation - try $\rho($ sample $)=1000 \mathrm{~kg} / \mathrm{m}^{3}$ - or (2) the much more elegant analytical solution which is known among physicists but does not adorn analytical chemistry textbooks.

1. Calculate the density of the TMAH solution using proper, buoyancy-corrected, weighing results.

2. Compare this result with the simplified result, by ignoring the buoyancy altogether.

3. Can you find the "elusive" analytical solution for calculating the density from the apparent masses (without buoyancy correction) which yields the buoyancycorrected density nonetheless?

\section{References}

1. Meija J (2009) Anal Bioanal Chem 393:405-406

2. Spieweck F, Bettin H (1992) Tech Mess 59:285-292

\section{Further Reading}

1. Nater R, Reichmuth A, Schwartz R, Borys M, Zervos P (2009) Dictionary of weighing terms. Springer, Dordrecht

2. Harris DC (1998) Quantitative chemical analysis. Freeman, New York

3. Picard A, Davis RS, Gläser M, Fujii K (2008) Metrologia 45:149155

We invite our readers to participate in the Analytical Challenge by solving the puzzle above. Please send the correct solution to abc-challenge@springer.com by August 1, 2013. Make sure you enter "The pycnometer challenge" in the subject line of your e-mail. The winner will be notified by e-mail and his/her name will be published on the ABC homepage at http:// www.springer.com/abc and in the journal (volume 405/issue 27), where readers will find the solution and a short explanation.

The next Analytical Challenge will be published in volume 405, issue 22 (September 2013). If you have enjoyed solving this Analytical Challenge, you are invited to try the previous puzzles on the ABC homepage. 